\title{
$330 \mathrm{MW}_{\text {th }}$ ÇAN DOLAŞIMLI AKIŞKAN YATAKLI TERMIKK SANTRAL KAZANININ HESAPLAMALI PARTİKÜL AKIŞKANLAR DİNAMİĞİ METODUYLA SAYISAL ANALİZİ
}

\author{
Barış GÜREL*, Osman İPEK
}

Süleyman Demirel Üniversitesi, Mühendislik Fakültesi, Makine Mühendisliği Bölümü, Isparta, Türkiye

\begin{tabular}{l} 
Anahtar Kelimeler \\
\hline Dolaşımlı akışkan yataklı \\
kazan, \\
Hesaplamalı partikül \\
akışkanlar dinamiği, \\
Yanma, \\
Partikül hidrodinamik akışı, \\
Sayısal analiz.
\end{tabular}

Sayısal analiz.

\begin{abstract}
Öz
Son y1llarda Türkiye linyitlerinin \%88'ini oluşturan düşük kaliteli linyitlerin temiz ve verimli bir şekilde yakılabilmesini sağlayan en önemli yakma teknolojisi olarak CFBB (Dolaşımlı Akışkan Yataklı Kazan) sistemleri öne çıkmaktadır. Bu çalışmada, çalışır durumda ve $330 \mathrm{MW}_{\text {th }}$ kapasitesindeki ÇTS (Çan Termik Santrali) CFBB sistemine ait otomasyon odasından alınan sınır koşulları ve yanma odası geometrik parametreleri dikkate alınarak, CPFD (Hesaplamalı Partikül Akışkanlar Dinamiği) metodu yardımıyla sistemin sayısal analizi gerçekleştirilmiştir. Analizlerde, yanma odasındaki basınç, sıcaklık, $\mathrm{O}_{2}, \mathrm{CO}_{2}, \mathrm{H}_{2} \mathrm{O}$ ve $\mathrm{SO}_{2}$ mol oranlarındaki değişimler incelenmiştir. Elde edilen analiz sonuçlara göre, ÇTS kazan tabanındaki basıncın $108401 \mathrm{~Pa}$, sicaklığın $1093 \mathrm{~K}$, mol oranları ise $\mathrm{O}_{2}$ için $0,01, \mathrm{CO}_{2}$ için $0,04, \mathrm{H}_{2} \mathrm{O}$ için 0,077 ve $\mathrm{SO}_{2}$ için 0,005 olduğu gözlemlenirken, kazan çıkışındaki ise sıcaklığın $1015 \mathrm{~K}$, mol oranlarının $\mathrm{O}_{2}$ için $0,08, \mathrm{CO}_{2}$ için $0,05, \mathrm{H}_{2} \mathrm{O}$ için 0,049 ve $\mathrm{SO}_{2}$ için 0,003 olduğu görülmüştür. Sunulan çalışmada kapsamında, pratik sonuçlarla oldukça uyumlu olduğu sayısal sonuçlar elde edilmiştir. Gerçekleştirilen matematiksel modellemede, yanma ve basınç özelliklerinin yanı sıra önemli emisyonlar ve partikül hidrodinamik akışı da modellenmiştir. Bu durum da CPFD metoduyla geliştirilen matematiksel modelin,akışın ve yanma prosesinin modellenmesinde çok büyük kolaylık oluşturduğunu göstermiştir. CPFD metoduyla doğrulanan sayısal model kullanılarak, 0,5-100 $\mathrm{MW}_{\text {th }}$ arasında değişen farklı kapasitede CFBB sistemlerinin tasarımları ve sınır koşullarının optimize edilebileceği sonucuna ulaşılmıştır.
\end{abstract}

\section{NUMERICAL ANALYSIS OF $330 \mathrm{MW}$ th ÇAN POWER PLANT CIRCULATING FLUIDIZED BED BOILER BY COMPUTATIONAL PARTICLE FLUID DYNAMIC METHOD}

\begin{tabular}{l}
\hline Keywords \\
Circulating fluidized bed \\
boiler, \\
Computational Particle \\
Fluid dynamics, \\
Combustion, \\
Particle hydrodynamic flow, \\
Numerical analysis.
\end{tabular}

Numerical analysis.

\begin{abstract}
CFBB (Circulating Fluidized Bed Boiler) systems that is foregoing as efficiency and enviromental combustion of the low quality lignites that have $\% 88$ in the Turkish lignites. In the present study, Çan TS numerical analysis were conducted by CPFD(Computational Particle Fluid Dynamics) method with it was reached that boundary conditions and geometrical knowledges of the Çan TS CFBB system by otomation and control room. Pressure, temperature, $\mathrm{O}_{2}, \mathrm{CO}_{2}, \mathrm{H}_{2} \mathrm{O}$ and $\mathrm{SO}_{2}$ mole fraction changing in the combustion chamber were investigated in the numerical analysis. In the study results, pressure, temperature, $\mathrm{O}_{2}, \mathrm{CO}_{2}, \mathrm{H}_{2} \mathrm{O}$ and $\mathrm{SO}_{2}$ mole fraction of the bottom of the furnace is relatively $108401 \mathrm{~Pa}, 1093 \mathrm{~K}, 0,01,0,04,0,077,0,005$ and pressure, temperature, $\mathrm{O}_{2}$, $\mathrm{CO}_{2}, \mathrm{H}_{2} \mathrm{O}$ and $\mathrm{SO}_{2}$ mole fraction of the exit of the furnace is relatively $103347 \mathrm{~Pa}, 1015 \mathrm{~K}, 0,081$, $0,05,0,049,0,003$. It is showed that very good compliance with numerical and practical results.Also, important emissions and particule hydrodynamic flow are modelled with combustion and pressure properties by improved mathematical model. It is showed that, mathematical model that is improved by CPFD method will have great benefits in modeling studies. As a result of the study, it is showed that optimizable of the small and large capacity $\left(0,5-100 \mathrm{MW}_{\mathrm{th}}\right)$ of the CFBB systems with CPFD method using validated numerical model.
\end{abstract}

\section{Alıntı / Cite}

Gürel B., İpek 0., (2019). 330 MWth Çan Dolaşımlı Akışkan Yataklı Termik Santral Kazanının Hesaplamalı Partikül Akışkanlar Dinamiği Metoduyla Sayısal Analizi, Mühendislik Bilimleri ve Tasarım Dergisi, 7(2), 441-451.

\begin{tabular}{l|l|l}
\hline Yazar Kimliği / Author ID (ORCID Number) & MakaleSüreci / Article Process \\
\hline B.Gürel, 0000-0002-1780-2603 & BaşvuruTarihi / Submission Date & 16.10 .2018 \\
O.İpek, 0000-0002-7069-1615 & RevizyonTarihi / Revision Date & 11.01 .2019 \\
& Kabul Tarihi / Accepted Date & 21.02 .2019 \\
& YayımTarihi / Published Date & 26.06 .2019 \\
\hline
\end{tabular}

\footnotetext{
*ilgili yazar / Corresponding author: barisgurel@sdu.edu.tr, +90-246-211-0805.
} 


\section{Giriş}

Enerjide dışa bağımlılık dikkate alınarak, düşük kalitedeki ve yerli linyit kömürlerin enerji üretiminde kullanılabilmesini sağlayacak yerli yakma teknolojilerinin geliştirilmesinin önemi gün geçtikçe artmaktadır. Bu kapsamda, en temiz kömür yakma teknolojisi olarak bilinen ve özellikle $\mathrm{NO}_{\mathrm{x}}$ ve $\mathrm{SO}_{2}$ açısından düşük emisyon değerlerine sahip olduğu ifade edilen CFBB sistemi dikkati çekmektedir. Yeni toz kömür yakma teknolojisi olarak da ifade edilen bu sistemde, özellikle yanma sonrası oluşan emisyon değerlerinin oldukça düşük olması nedeniyle bu sistemin yerlileştirilmesi üzerindeki çalışmaları oldukça önemli hale getirmiştir. Diğer taraftan, 2019 yll sonuna kadar, $\mathrm{CO}, \mathrm{NO}_{\mathrm{x}}$ ve $\mathrm{SO}_{\mathrm{x}}$ emisyon limitlerinin sirasiyla, 200, 800 ve $1000 \mathrm{mg} / \mathrm{Nm}^{3}$ olarak belirlenmiş(Directive 2010/75/EU of the European Parliament and of the Council of 24 November 2010, 2010) olması(AB LCP Direktifi, 2001), CFBB sistemi üzerinde yapılacak çalışmaların önemini daha da arttırmaktadır. Yapılan araştırmalara göre, son yıllarda Dünya genelinde CFBB sisteminin kullanılmasına yönelik eğilimin hızla arttığı görülmektedir.

\section{Bilimsel Yazın Taraması}

Giriş̧ kısmında verilen bilgiler ışı̆̆ında değerlendirildiğinde, özellikle son yllarda, CFBB sistemlerinin sayisal ve deneysel olarak incelenmesiyle ilgili çalışmaların yapıldığı gözlemlenmektedir.

Özkan (2010)tarafından yapılan tez çalışmasında, yüksek ısıl değerli kömürü kumda yakabilen, dikdörtgen paralel yüzlere sahip 0.3 $\mathrm{MW}_{\text {th }}$ kapasiteli Dolaşımlı Akışkan Yataklı Yakıcı(DAYY) üzerinden alınan ve deneysel verilerle geçerliliği ispatlanmıș bir kazan modelinin, silindirik forma dönüştürülmesi, NO oluşum ve indirgenme reaksiyonlariyla siklon, iniş borusu ve geri dönüş borusu vanası etrafındaki basınç düşüşünün belirlenmesine yönelik çalışmalar gerçekleştirmiştir. Araştırmacı bu model için yapmış olduğu öngörülerinin doğruluğunu, ODTÜ bünyesinde bulunan, düşük kalorili ve yüksek uçucu madde/sabit karbon oranına sahip yerli linyit kömürü yakabilen150 $\mathrm{kW}_{\text {th }}$ kapasiteli DAYY'a ait analiz ve ölçüm sonuçlarıyla kıyaslayarak test etmiştir. Sıcaklık ve basınç dağılımları ile gaz emisyonlarının öngörülen ve ölçülen değerleri arasında karşılaştırmalar yapılmış olumlu sonuçlar elde edilmiștir. Model üzerinde basınç doğrulmasıyla elde edilen sonuçların, seyrek tanecikli bölgede, katı parçacık miktarının yukarı yönlü azalmasının belirlenmesinde kullanılacak korelasyonlar üzerinde etkili olduğu ortaya konulurken, NO emisyonuna ait öngörülerin doğrulanması ise kömürdeki azotun kok azotuna ve uçucu azota oranına ve seyrek tanecikli bölgedeki oksijen içeriğine güçlü bir şekilde bağlı olduğunu gösterilmiştir(Özkan, 2010).
Pandey ve Kumar (2011) tarafindan yapılan çalışmada, CFBB' de kömürün yanması incelenmişlerdir. Farklı akışkanlaşma hızlarında, yatak içerisindeki sıcaklığın ve basıncın değişiminin araștırıldığı çalıșmada, standart k- $\varepsilon$ iki fazlı türbülans metodu, Discrete Phase ve non-premixed modelleri kullanılarak kömürün yanmasını modellenmişlerdir. Ölçeklendirilmiş Varyans yapısı boyunca minimum ortalama yoğunluk ve maksimum ortalama karışım oranı değerleri gözlemlenmiştir (Pandey ve Kumar, 2011).

Weng ve Plackmeyer (2011) tarafindan gerçekleştirilen çalışmada, Barracuda CPFD programı ile yapılan 3D(üç boyutlu) sayısal analizlerde, Duisburg Dolaşımlı Akışkan Yataklı Santrali kazanından alınan deneysel sonuçlar karşılaştırılmış, sonuçların çok uyumlu olduğunu ortaya konulmuştur. $\mathrm{Bu}$ sonuçlar dikkate alınarak, Barracuda CPFD programının gelecekteki optimizasyon çalışmalarında ,akışkan yatakta hidrodinamik, sıcaklık ve emisyon değerlerinin belirlenmesinde önemli bir araç olduğu belirtilmiştir (Weng ve Plackmeyer, 2011).

Feng v.d. (2012) tarafından yapılan çalışmada,AnsysFluent programinda Eulerian-Eulerian metodu kullanılarak laboratuvar ölçekli içten dolaşımlı akıșkan yataklı sistemde, gaz-katı akıșının 2D CFD modellemesi yapılmışlardır. Yapılan çalışma, yatak malzemesi olan kumun akışkan yatakta,farklı geometrilerde zamana göre hacimsel dağılımını gösterilmişler, kumun farklı akışkanlaşma hızında farklı akım çizgilerinde dolaşım yaptı̆̆ belirlenmiştir(Feng vd., 2011).

Gasparini vd. (2012), CFBB sistemini kullanarak kömürün yanması sonucu olușan baca gazı miktarının azaltılması için çalışmalar yapmışlardır. CFBB sistemiyle baca gazlarının azaldığını yaptığı deneylerde göstermiş ,kazan içerisinde sıcaklık ile baca gazı miktarı arasındaki ilişkiyi tanımlayan korelasyonlar türetmişlerdir(Gasparini vd., 2012).

Jiang v.d. (2014)tarafından yapılan çalışmada, büyük ölçekli CFBB boylerlerinin dizayn ve performansını arttırmak CPFD ve Electric Capacitan Cetomography(ECT) metotlarını kombine ederek altı siklon ayırıcılı CFBB sisteminde gaz-katı hidrodinamik davranışını incelemek için yeni bir yaklaşım geliştirilmiştir. Dizayn ve performans arttırma çalışması, CFBB sisteminin simülasyonu CFBB akışkanlaştırıcısının tasarımını, taşıma borusu ve $U$ döngü borusunun dizaynını içermektedir. CPFD simülasyonunu için taşıma borusunun dişına 8 adet elektrot monte edilerek ECT metodu ile tașıma borusundaki partikül konsantrasyonunu ölçülmüştür.

$\mathrm{Bu}$ çalışmada araștırmacılar, CPFD simülasyon analizleri ile deneysel sonuçların karşılaştırılmasında anahtar parametrelerin, basınç, partikül dolaşımı ve farklı pozisyonlardaki akış hızı olduğunu 
belirtmişlerdir. CPFD simülasyonları altı paralel siklondaki gaz-partikül akışının üniform olmadığını göstermiştir. 4 siklonda, akışkanlaştırıcı kolonu bağlayan köședeki partikül konsantrasyonun diğerlerinden daha yüksek olduğu gösterilmiş, siklon bölgesinin ve siklona giriş açısının optimize edilmesi gerektiği belirtilmiştir. Bu tespitten hareket edilerek sistem optimize edilmiştir. Bu çalışma süper kritik basınçtaki CFBB sistemlerinde siklon separatör düzeninin optimize edilmesi için CPFD simülasyonu ve ECT ölçümünün kullanılabileceği gösterilmiștir(Jiang vd., 2014).

Gan vd. (2016), yaptıkları çalışmalarında, elipsoidal partiküllerin akışkan yatakta ısı transferini CFD-DEM metodunu kullanarak incelemişlerdir. Elde edilen sonuçlara göre, partikül geometrisinin yatağın efektif termal iletkenliğini önemli ölçüde etkilediği belirtilmiştir. Elipsoit geometrili partiküllerin daha düşük taşınım katsayısına sahip olduğu, bunun yanı sıra iletim katsayısının ise daha yüksek olduğu, elipsoit belirtilmiştir(Gan vd., 2016).

Gül ve Özdoğan (2016), yaptıkları çalışmada, CFBB sisteminde ejektör tipi partikül sirkülasyon sisteminin sayısal ve deneysel analizini yapmışlardır. Çalışma ile deneysel sonuçlardan yeni bir yarı ampirik model önerilmiş, bu modelle tahmin edilen ejektör performansı CFD analizlerinden elde edilen sonuçlarla karşılaştırılmıştır. Deneysel sonuçlara göre, partikül sütununda, aynı miktardaki gaz akışına göre daha yüksek basınç düşüşü ortaya çıktığı belirtilmiştir. CFD analizlerinde ejektör tarafından oluşturulan vakum basıncının gaz akışına ait kütlesel debisinin artışıyla doğrusal olarak arttığ belirtilmiştir(Gül ve Özdoğan, 2016).

Farid vd. (2017) tarafından yapılan çalışmada, endüstriyel ölçekli $340 \mathrm{MW}_{\mathrm{e}}$ kapasitesindeki CFBB sistemli yakıcıda kömür besleme konumları ve kömür besleme oranlarının partikül transport hidrodinamiği ve yanma prosesinin etkileri 3D sayısal analizleri yapılmıştır. $\mathrm{Bu}$ kapsamda gerçekleştirilen, simülasyonlarda, DDPM(Dense Discrete Phase Model) kullanılmıştır. Çalışmada iki farklı kömür besleme pozisyonu ve kömür besleme oranı üzerinde araştırmalar gerçekleştirilmiştir. Elde edilen sonuçlarla, tasarımdaki değişimlerle yakıcının üst bölgelerinde ısı transferinin arttırıldığı gösterilmiştir (Farid vd., 2017).

Kraft vd. (2017)tarafından yapılan çalışmada, 8 MW th kapasitedeki endüstriyel ölçekli ikili akışkan yataklı buhar gazlaştırma sisteminin CPFD metoduyla simülasyonu yapılmıştır. Yapılan çalışmada hidrodinamik tahminlerin seçilen EMMS (EnergyMinimization Multi-Scale) sürüklenme metoduna güçlü bir şekilde bağlı olduğunu , bu metotla yapılan tahminlerin yataktaki malzeme sirkülasyonu ve basınç düșüșü için deneysel sonuçlara en yakın sonuçları verdiği belirtilmiştir. Yapılan araştırmalara göre, CPFD metodunun gelecekte endüstriyel boyuttaki ikili akışkan yatak sistemlerinin tasarımı ve analizinde etkili bir metot olacağı belirtilmiştir. Bu metodun, sıcaklık, basınç ve gaz kompozisyonunun tahminlerinin çok iyi bir araç olduğu gösterilmiştir(Kraft vd., 2017).

Literatürde yapılan çalışmalar değerlendirildiğinde, faal durumdaki CFBB sistemlerinin sayısal analiziyle ilgili detaylı bir çalışmanın yapılmadığı gözlemlenmiştir.

Analiz doğrulamayı da amaçlayan bu yeni çalışmada, sıcaklık, basınç, debi ve emisyon parametreleri ve bunlara ait sınır koșulları dikkate alınarak faal durumdaki $330 \mathrm{MW}_{\text {th }}$ kapasiteli ÇTS CFBB sisteminin yanma odası geometrisi için CPFD metoduna dayanan analiz çalışmaları yapılmış, sisteme ait pratik sonuçlar ile sayısal sonuçlar karşılaştırılmıştır. Elde edilen sonuçlara göre, sayısal analiz sonuçları ile pratik sonuçların uyumlu olduğu sonucuna ulaşılmıştır. ÇTS CFBB sistem geometrisi, sınır koşulları ve kazan içerisinde oluşan sıcaklık ve basınç parametreleri santralin otomasyon odasından alınmıștır.

\section{Materyal ve Yöntem}

\section{1. ÇTS CFBB Geometrisi ve Sayısal Analizlerde Kullanılan Sınır Koşulları}

ÇTS üzerinde yapılan bu araştırmada otomasyon odasından alınan sistem geometrisi ve sınır koşulları dikkate alınarak ilk tasarımla kazan içerisindeki akışın sayısal analizi yapılmıştır.

ÇTS kazan geometrisi ve otomasyon odasındaki sınır koșulları șeması sırasıyla Șekil 1 ve Şekil 2(a)'da gösterilmiștir. Bunun yanı sıra, CTS'de kullanılan kömürün proksimite ve elementel analiz değerleri, sayısal analizde kullanılan sınır koşulları ile $\mathrm{CO}, \mathrm{CO}_{2}$, $\mathrm{NO}_{\mathrm{x}}$ ve $\mathrm{SO}$ molar oranlarının belirlenmesi için kullanılan reaksiyonlar, kullanılan yatak malzemesi, ve partikül çapı sırasıyla, Tablo 1'de, Tablo 2ve Tablo 3 ve Tablo 4 'te verilmiștir.

Kum-gaz ve kömür arasındaki hareketi modellemek için EMMS-Yang 2004 modeli kullanılmıştır. Geliștirilmiş bu sürüklenme modeli son yıllarda yaygın olarak kullanılmaktadır. Bu modelde kullanılan denklemler Tablo 5 'te verilmiştir. 


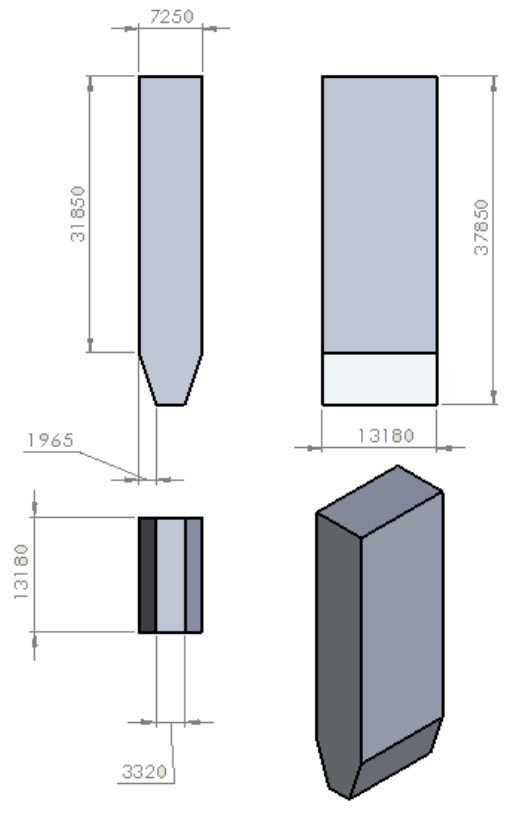

Şekil 1. ÇTS CFBB sistem geometrisi

Sekil 1'de verilen CTS CFBB sistem geometrisinde görüldüğü gibi kazanın taban boyu 13,18 m, kazanın taban eni 3,32 m olarak ölçülmüştür . Yanma odası sonuna kadar uzanan kazan yüksekliği $6 \mathrm{~m}$, yanma odası sonunda kazan eni 7,25 m kazanın toplam yüksekliği ise 37,85 m'dir. ÇTS otomasyon odasından alınan bilgilerde toz dolaşım sistemi geri dönüş hattında bulunan siklon, seal-pot ve geri dönüş borusu geometrileri hakkında yeterli bilgi elde edilememiștir. Bununla birlikte, mevcut veriler kullanılarak kazan içi analizi yapılabilmektedir.

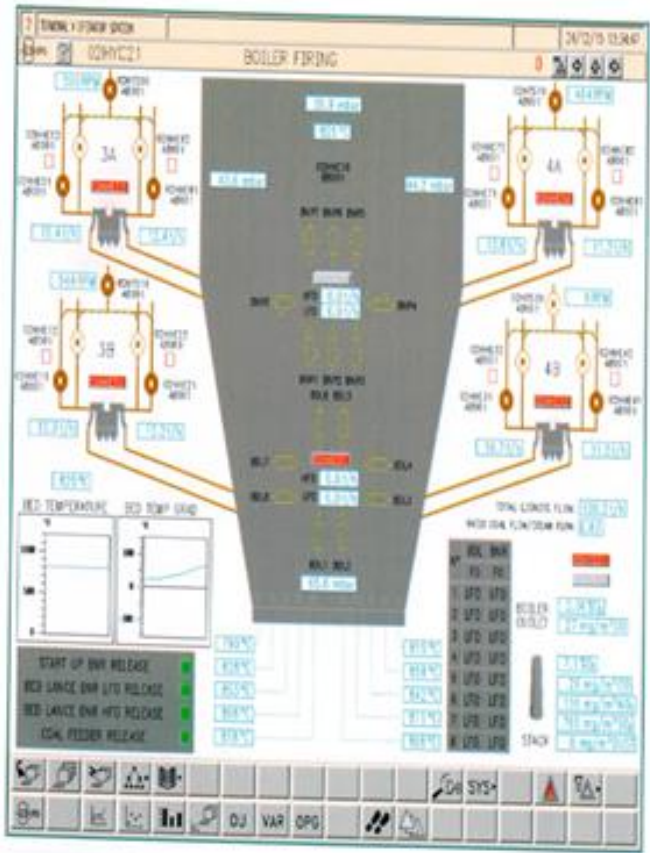

Şekil 2. ÇTS otomasyon odasındaki yanma odası sınır koşullarının otomasyon şeması
Şekil 2'de ÇTS Otomasyon odası sınır koşulları şemasında görüldüğü gibi, kazan içine gönderilen toplam hava miktarı 542,6 ton/h'tir. Bu havanın 229,5 ton/h'lik kısmı primer akışkanlaştırıcı gören 129 mbar basınçtaki primer havadan oluşmaktadır. Geriye kalan 312,9 ton/h'lik kısmı yanma odası kısmına farklı portlar'dan gönderilen sekonder havadan oluşmaktadır. Bununla birlikte, aynı şekilde verildiği gibi, ÇTS yanma odasına linyit kömürü seal-potlardan yatak malzemesi ve kireç taşı ile karıştırılarak beslenmektedir. Beslenen toplam linyit kömürü debisinin 109,2 ton/h olduğu görülmektedir. Bunun yanı sıra, Şekil 3'de görüldüğü gibi, kazan içerisindeki basınç değerlerinin kazan tabanında bulunan akıșkanlaștırıcılardan sonra yatak tabanında 65,6 mbar, seal-potundan sonra yaklaşık $8 \mathrm{~m}$ yükseklikte 44 mbar ve kazanın orta noktalarında ise 20,9 mbar değerini aldığı görülmektedir.

Tablo 1.Çan linyit komürüne ait proksimite ve elementel analiz sonuçları

\begin{tabular}{|l|c|}
\hline \multicolumn{2}{|c|}{ Elementel Analiz(\%) } \\
\hline C (Carbon) Kütlesel Oranı & 72,9 \\
\hline H (Hydrogen) Kütlesel Oranı & 5,76 \\
\hline O ( Oxygen) Kütlesel Oranı & 11,7 \\
\hline N (Nitrogen) Kütlesel Oranı & 2,1 \\
\hline S (Sulphur) Kütlesel Oranı & 7,54 \\
\hline Proksimite (Yaklaşı) Analiz( Kuru ve Külsüz) (\%) \\
\hline Sabit Karbon Kütlesel Oranı & 30,05 \\
\hline Uçucu Madde Kütlesel Oranı & 28,79 \\
\hline Kül Kütlesel Oranı & 26,9 \\
\hline Nem Kütlesel Oranı & 14,26 \\
\hline
\end{tabular}

Tablo 1'de Çan linyiti kömürünün elementel ve proksimite içeriği verilmiştir.

Tablo 2. CTS kazanı sayısal analizinde kullanılan sınır koşulları

\begin{tabular}{|l|c|}
\hline $\begin{array}{l}\text { Primer(Akışkanlatırıcı) Hava Kütlesel } \\
\text { Debisi(kg/s) }\end{array}$ & 63,75 \\
\hline Sekonder Hava Kütlesel Debisi(kg/s) & 86,91 \\
\hline Primerve Sekonder Hava Sıcaklığı (K) & 513,15 \\
\hline Yatak Materyali Sıcaklığı (K) & 1123 \\
\hline Kömür Kütlesel Debisi(kg/s) & 30,33 \\
\hline Kazan Beslenen Kireç Miktarı(CaCO $\left.{ }_{3}\right)(\mathrm{kg} / \mathrm{s})$ & 10 \\
\hline Kömür ve Kireç(CaCO $\left.{ }_{3}\right)$ Sıcaklığı (K) & $300 \mathrm{~K}$ \\
\hline Kazan Çıkıș Basıncı (mbar) Pä) & 20,9 \\
\hline $\begin{array}{l}\text { Kazan Tabanında Proses Başlamadan Önce } \\
\text { Bulunan Yatak Materyali Yüksekliği (m) }\end{array}$ & 1 \\
\hline
\end{tabular}

Tablo 2'de verilen, ÇTS otomasyon odasından alınan değerler kullanılarak sayısal analizler yapılmıștır. Tablo 2'de verilen sınır koşulları dikkate alınarak CFBB sistemine ait analizlerde kullanılan geometrik sınır koşulları geometrinin ağ yapısı sırasıyla Şekil 3 ve Şekil 4 'te verilmiștir. 


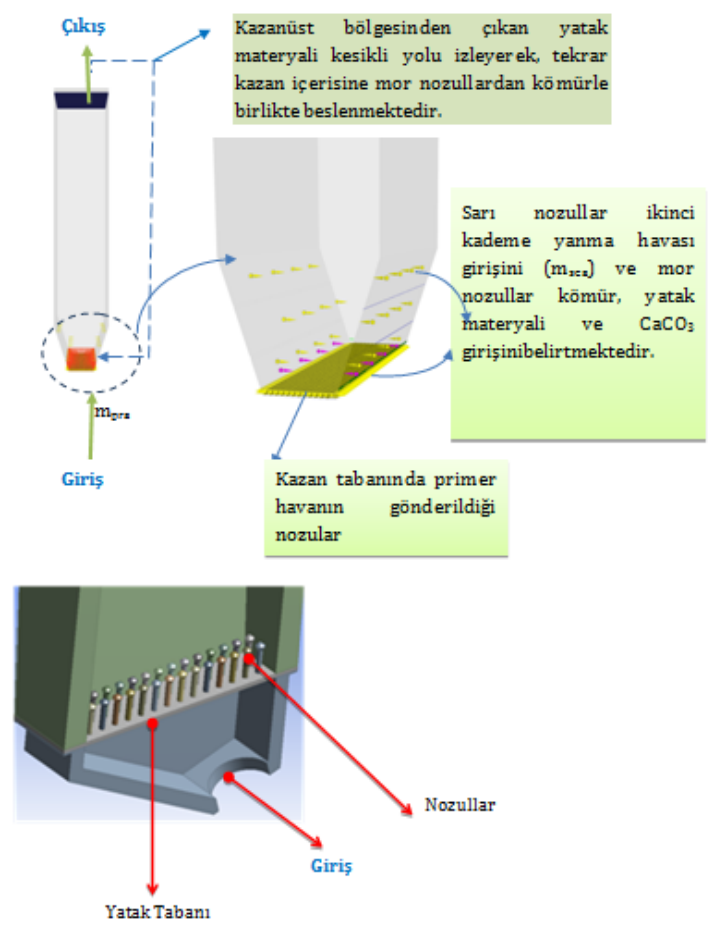

Şekil 3. ÇTS CFBB sistemi sınır koşulları

Tablo 2'de verilen verilen ve ÇTS otomasyon biriminden alınan sınır koşullarına göre, kazan girişindeki primer hava debisi $63,75 \mathrm{~kg} / \mathrm{s}$ ve sıcaklığ 513,15 K'dir. Kazan tabanında bulunan 720 tane nozulla havanın homojen olarak CFBB yatağına gönderildiği görülmektedir. Yakıt $0,33 \mathrm{~kg} / \mathrm{s}$ kütlesel debide ve $300 \mathrm{~K}$ sicaklıkta kazan tabanının $1 \mathrm{~m}$ üzerindeki iki giriş noktasından $1 \mathrm{~m} / \mathrm{s}$ hızla beslenmektedir. Kazan tabanına göre $2 \mathrm{~m}$ yükseklikteki sağ ve sol kazan duvarlarında bulunan iki giriş noktasından 86,91 kg/s debisinde ve 513,15 K sıcaklıkta sekonder hava gönderilmektedir.

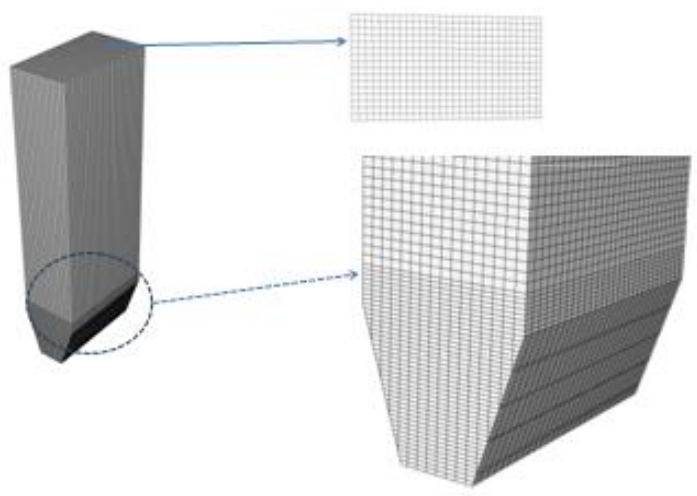

Şekil 4. Çan CFBB sistemine ait sayısal ağ yapısı

Şekil 4'te görüldüğü gibi, sayısal analizlerde kullanılmak üzere oluşturulan Çan CFBB sistemine ait ağ yapısı 400000 dörtgen ağ elemanından oluşmaktadır. Kazanın genişleyen taban kısmının sayısal ağ yapısı diğer kısımlara göre oldukça daha sık olacak șekilde ağ yapısı oluşturulmuştur. Dörtgen elemanlardan oluşan sayısal ağ yapısı doğru çözümlemelere ulaşmak için en uygun ağ yapısı olarak belirlenmiștir.
Tablo 3. Sayısal analizlerde kullanılan kimyasal reaksiyonlar

\begin{tabular}{|c|c|}
\hline Kimyasal Reaksiyon & Reaksiyon Oranı \\
\hline \begin{tabular}{llll}
$\mathrm{C}_{0.02}$ & $\mathrm{H}_{5.44}$ & $\mathrm{O}_{1} \mathrm{~N}_{0.1958}$ & $\mathrm{~S}_{0.1677}$ \\
$+1,04 \mathrm{O}_{2} \rightarrow 0,02 \mathrm{CO}_{2}+2,72 \mathrm{H}_{2} \mathrm{O}+$ \\
\multicolumn{4}{l}{$0,0979 \mathrm{~N}_{2}+0,1,677 \mathrm{SO}_{2}$}
\end{tabular} & $\begin{array}{l}\text { 0,05T e } \mathrm{e}^{(-5500 / \mathrm{T})}\left(\left(\mathrm{s}^{-1}\right) \text { CPFD Barracuda User }\right. \\
\text { Guide, 2015) }\end{array}$ \\
\hline $2 \mathrm{C}_{(\mathrm{s})}+\mathrm{O}_{2} \rightarrow 2 \mathrm{CO}$ & $\begin{array}{lllll}4,34 & 10^{7} & \mathrm{~T} & \theta_{\mathrm{c}} \theta_{\mathrm{f}} & \left(\mathrm{N}_{\mathrm{p}} / \mathrm{V}_{\text {cell }}\right)^{-1} \mathrm{e}^{-} \\
13590 / \mathrm{T})[02]\left(\mathrm{mol} \mathrm{s}^{-1}\right) & (\text { Güngör ve Eskin, 2008) }\end{array}$ \\
\hline $\mathrm{CO}+0,5 \mathrm{O}_{2} \rightarrow \mathrm{CO}_{2}$ & $\begin{array}{l}\text { 2,238 } 10^{8} \mathrm{e}^{(-5031 / \mathrm{T})[\mathrm{CO}][02] 0,25[\mathrm{H} 20] 0,5}\left(\mathrm{~mol} \mathrm{~m}^{-3} \mathrm{~s}^{-}\right. \\
\text {1) (Güngör ve Eskin, 2008) }\end{array}$ \\
\hline $\mathrm{H}_{2}+0,5 \mathrm{O}_{2} \rightarrow \mathrm{H}_{2} \mathrm{O}$ & $\begin{array}{l}7,910^{10} \mathrm{e}^{(-17614 / \mathrm{T})} \quad[\mathrm{H} 2] \quad[02] 0,5\left(\mathrm{~mol} \quad \mathrm{~m}^{-3} \mathrm{~s}^{-1}\right) \\
\text { (Ducarne vd., 1998) }\end{array}$ \\
\hline $\mathrm{HCN}+0,5 \mathrm{O}_{2} \rightarrow \mathrm{CNO}$ & 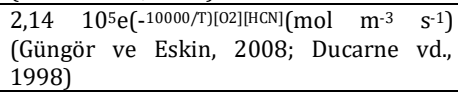 \\
\hline $\mathrm{CNO}+0,5 \mathrm{O}_{2} \rightarrow \mathrm{NO}+\mathrm{CO}$ & $\begin{array}{l}(\mathrm{k}[\mathrm{O} 2][\mathrm{HCN}]) /\left(1+\frac{k_{2}}{k_{1}}[\mathrm{NO}]\right)\left(\mathrm{mol} \mathrm{m}^{-3} \mathrm{~s}^{-1}\right) \\
\text { (Güngör ve Eskin, 2008; Ducarne vd., } \\
\text { 1998) }\end{array}$ \\
\hline $\mathrm{CNO}+\mathrm{NO} \rightarrow \mathrm{N}_{2} \mathrm{O}+\mathrm{CO}$ & $\begin{array}{l}(\mathrm{k}[\mathrm{O} 2][\mathrm{HCN}])\left(\frac{\frac{k_{2}}{k_{1}}[\mathrm{NO}]}{\left(1+\frac{k_{2}}{k_{1}}[\mathrm{NO}]\right)}\right)\left(\mathrm{mol} \mathrm{m}^{-3} \mathrm{~s}^{-1}\right) \\
\text { (Güngör ve Eskin, 2008; Ducarne vd., } \\
\text { 1998) }\end{array}$ \\
\hline $\mathrm{N}_{2} \mathrm{O}+\mathrm{C}_{(\mathrm{s})} \rightarrow \mathrm{N}_{2}+\mathrm{CO}$ & $\begin{array}{l}2,910^{9} \mathrm{e}^{(-16983 / \mathrm{T})}\left(\mathrm{N}_{p} / V_{\text {cell }}\right)^{1}\left[\mathrm{~N}_{2} \mathrm{O}\right]^{\pi} d_{C}^{2}\left(\mathrm{mols}^{-}\right. \\
\text {1) (Liu vd., 2005) }\end{array}$ \\
\hline $\mathrm{N}_{2} \mathrm{O}+\mathrm{CO} \rightarrow \mathrm{N}_{2}+\mathrm{CO}_{2}$ & 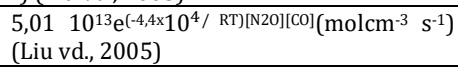 \\
\hline $\mathrm{N}_{2} \mathrm{O}+0,5 \mathrm{O}_{2} \rightarrow \mathrm{N}_{2}+\mathrm{O}_{2}$ & $\begin{array}{l}1 \times 10^{14} \mathrm{e}^{\left(-2,8 \times 10^{4} / \mathrm{RT}\right)}[\mathrm{N20][02]} \text { (Kilpinen vd., } \\
2002)\end{array}$ \\
\hline $\mathrm{NO}+\mathrm{C}_{(\mathrm{s})} \rightarrow 0,5 \mathrm{~N}_{2}+\mathrm{CO}$ & $\begin{array}{lrr}5,85 & \mathrm{x} & 10^{7} \mathrm{e}^{(-12000 / \mathrm{T})} \\
\left(N_{p} / V_{\text {cell }}\right)^{1}[N O]^{\pi} d_{C}^{2}\left(\mathrm{molcm}^{-3} \mathrm{~s}^{-1}\right) \text { (Ducarne } \\
\text { vd., 1998) }\end{array}$ \\
\hline $\mathrm{NO}+0,5 \mathrm{C}_{(\mathrm{s})} \rightarrow 0,5 \mathrm{~N}_{2}+0,5 \mathrm{CO}_{2}$ & $\begin{array}{l}1,3 \times 10^{5} \mathrm{e}^{(-17111 / \mathrm{T})}\left(N_{p} / V_{\text {cell }}\right)^{1}[\mathrm{NO}]^{\pi} d_{C}^{2}(\mathrm{~mol} \\
\left.\mathrm{s}^{-1}\right) \text { (Kilpinen vd., 2002) }\end{array}$ \\
\hline $\mathrm{NO}+\mathrm{CO} \rightarrow 0,5 \mathrm{~N}_{2}+\mathrm{CO}_{2}$ & $\begin{array}{l}1,15 \times 10^{7} \mathrm{e}^{(-22800 / \mathrm{T}) \mathrm{mc}} \mathrm{NO}^{0,39}[\mathrm{CO}] 0.53\left(\mathrm{~mol} \mathrm{~m}^{-3}\right. \\
\left.\mathrm{s}^{-1}\right) \text { (Johnson ve Dam-Johansen, 1991;Duo } \\
\text { vd., 1992) }\end{array}$ \\
\hline $\mathrm{NH}_{3}+1,25 \mathrm{O}_{2} \rightarrow \mathrm{NO}+1,5 \mathrm{H}_{2} \mathrm{O}$ & $\begin{array}{l}2,73 \times 10^{14} \mathrm{e}^{(-38160 / \mathrm{T})}[\mathrm{NH} 3][02]\left(\mathrm{mol} \mathrm{m}^{-3} \mathrm{~s}^{-1}\right) \\
\text { (Kilpinen vd., 2002; Duo vd., 1992) }\end{array}$ \\
\hline $\begin{array}{l}\mathrm{NH} 3+0,75 \mathrm{O} 2 \rightarrow 0,5 \mathrm{~N}_{2}+1, .5 \\
\mathrm{H}_{2} \mathrm{O}\end{array}$ & $\begin{array}{l}\left(3,38 \times 10^{7} \mathrm{e}^{(-10000 / \mathrm{T})}[\mathrm{NH} 3][02]\right) /([02]+0,054)(\mathrm{mol} \\
\left.\mathrm{m}^{-3} \mathrm{~s}^{-1}\right) \text { (Güngör ve Eskin, 2008; Ducarne } \\
\text { vd., 1998) }\end{array}$ \\
\hline $\begin{array}{l}\mathrm{NO}+\mathrm{NH}_{3}+0,5 \mathrm{O}_{2} \rightarrow \mathrm{N}_{2}+1,5 \\
\mathrm{H}_{2} \mathrm{O}\end{array}$ & $\begin{array}{l}1,1 \times 10^{12} \mathrm{e}(-27680 / \mathrm{T}) \sqrt{\left[\mathrm{O}_{2}\right]} \sqrt{\left[\mathrm{NH}_{3}\right]} \sqrt{\mathrm{NO}}(\mathrm{mol} \\
\mathrm{m}^{-3} \mathrm{~s}^{-1} \text { ) Johnson ve Dam-Johansen, } \\
\text { 1991;Duo vd., 1992) }\end{array}$ \\
\hline $\mathrm{CaCO}_{3} \rightarrow \mathrm{CaO}+\mathrm{CO}_{2}$ & $\begin{array}{l}6,07810^{7}\left(\mathrm{P}_{\mathrm{e}}-\mathrm{P}_{\mathrm{CO2}}\right) / \mathrm{P}_{\mathrm{e}} \mathrm{e}^{(-205000 /(\mathrm{RT}))}\left(\mathrm{mol} \mathrm{s} \mathrm{s}^{-1}\right) \\
\text { (Dennis ve Hayhurst, 1990; Borgwardt vd., } \\
\text { 1987) }\end{array}$ \\
\hline $\mathrm{CaO}+\mathrm{SO}_{2}+0,5 \mathrm{O}_{2} \rightarrow \mathrm{CaSO}_{4}$ & $\begin{array}{l}14,9 \sigma\left[\mathrm{SO}_{2}\right] \mathrm{S}\left(\mathrm{mol} \mathrm{s}^{-1}\right) \text { (Dennis ve Hayhurst, } \\
\text { 1990; Borgwardt vd., 1987) }\end{array}$ \\
\hline \multicolumn{2}{|c|}{$\begin{array}{l}\mathrm{k}=2,14 \times 10^{5} \mathrm{e}(-10000 / \mathrm{T}), \quad \frac{k_{2}}{k_{1}}=1,02 \times 10^{9} \mathrm{e}^{(-25460 / \mathrm{T}),} \quad \sigma=\frac{\mathrm{K}_{\mathrm{s}} \mathrm{d}_{\mathrm{CaCO} 3}}{6 \mathrm{De}}, \\
\mathrm{K}_{\mathrm{s}}=0,02 \mathrm{e}\left(-\frac{38000}{\mathrm{RT}}\right) \cdot \mathrm{D}_{\mathrm{e}}=1,18 \times 10^{-5} \mathrm{e}\left(-\frac{33000}{\mathrm{RT}}\right)\end{array}$} \\
\hline
\end{tabular}

Tablo 3'te verilen reaksiyonlar kullanılarak $\mathrm{CO}, \mathrm{CO}_{2}$, $\mathrm{H}_{2} \mathrm{O}, \mathrm{SO}_{\mathrm{x}}$ ve $\mathrm{NO}_{\mathrm{x}}$ emisyonları sayısal olarak modellenmiştir. $\mathrm{Bu}$ reaksiyonlarda kullanılan mc, karbonun kütle debisini, mkül, külün kütle debisini, $\mathrm{Pe}, \mathrm{CO2}$ 'in dengeli kompozisyon basincinı ve PCO2, $\mathrm{CO}_{2}$ 'in kısmi basıncını, S, kireç BET (Brunauer, Emmett and Teller)-yüzey alanını, $\sigma$ ise bir katsayıyı belirtmektedir. S, kireç BET-yüzey alanı (Chen vd., 2012)'nin çalışmasından $0.4 \mathrm{~m}^{2} /$ gr olarak alınmıştır.

$\sigma=\frac{K_{S} d_{C a C O} 3}{6 D e}$

Denklem 1'de verilen Ks ve De(Dennis ve Hayhurst, 1990; Borgwardt vd., 1997)

$\mathrm{K}_{\mathrm{S}}=0.02 \exp \left(-\frac{38000}{\mathrm{RT}}\right), \mathrm{D}_{\mathrm{e}}=1.18 \times 10^{-5} \exp \left(-\frac{33000}{\mathrm{RT}}\right)$ olarak verilmiștir. 
Tablo 4. Kazan içerisinde kullanılan kömür, yatak malzemesi ve kireç $\left(\mathrm{CaCO}_{3}\right)^{\prime}$ in özellikleri

\begin{tabular}{|c|c|c|c|}
\hline Partikül Tipi & Çan Linyiti & Yatak Malzemesi & Kireç \\
\hline Yoğunluk $\left(\mathrm{kg} / \mathrm{m}^{3}\right)$ & 1479.54 & 2598.4 & 2711 \\
\hline Partikül Çapı $(\mathrm{m})$ & 0,002 & $60 \times 10^{-6}$ & $200 \times 10^{-6}$ \\
\hline
\end{tabular}

Tablo 4'te görüldüğü gibi, Çan otomasyon biriminden alınan bilgilere göre, analizlerde linyit yakıtın ortalama partikül çapı $0,002 \mathrm{~m}$, yatak malzemesi partikül çapı $60 \times 10^{-6} \mathrm{~m}$ ve kireç partikül çapı ise 200 x $10^{-6}$ olarak alınmıştır. Analizlerde, yanma prosesi rejime ulaştığında, yanmış kömürün $60 \mu$ çapındaki külünün yatağa beslendiği dikkate alınmıştır. Bunun yanı sıra, ÇTS otomasyon birimi tarafından, yatağa beslenmesi gereken kirecin $200 \mu$ çapında olması gerektiği ifade edilmiştir. Yapılan sayısal analizlerde de bu koşullar dikkate alınmıştır.

\subsection{Sayısal Analiz Yöntemi}

Sayısal analizlerde, gaz-katı karışımına ait çok fazlı bir akışın analiz edilebilmesi için MP-PIC(MultiphaseParticle In Cell) metodu kullanılmıştır. Bu metotta, gaz fazı için kütle ve momentum hesaplamaları için kullanılan bağıntılar sırasıyla Deklem 2 ve Denklem 3'te verilmiștir (Williams, 1985; Batchelor, 1988; Gidaspow, 1994; Karimipour ve Pugsley, 2012).

$\frac{\partial\left(\theta_{\mathrm{f}} \rho_{\mathrm{f}}\right)}{\partial_{\mathrm{t}}}+\nabla\left(\theta_{\mathrm{f}} \rho_{\mathrm{f}} \mathrm{u}_{\mathrm{f}}\right)=0$

$\frac{\partial\left(\theta_{\mathrm{f}} \rho_{\mathrm{f}}\right)}{\partial_{\mathrm{t}}}+\nabla\left(\theta_{\mathrm{f}} \rho_{\mathrm{f}} \mathrm{u}_{\mathrm{f}}\right)=-\nabla \mathrm{P}+\nabla \cdot\left[\theta_{\mathrm{f}} \mu_{\mathrm{f}} \nabla \mathrm{u}_{\mathrm{f}}\right]+$

$\nabla \cdot\left[\theta_{\mathrm{f}} \mu_{\mathrm{f}}\left(\nabla \mathrm{u}_{\mathrm{f}}\right)^{\mathrm{T}}\right]-\nabla\left\{\frac{2}{3} \theta_{\mathrm{f}} \mu_{\mathrm{f}} \nabla \cdot \mathrm{u}_{\mathrm{f}}\right\}-\mathrm{F}$

Denklem (2) ve Denklem (3)'te verilen parametrelerden, $\mathrm{u}_{\mathrm{f}}, \rho_{\mathrm{f}}$ ve P sırasıyla, akışkanın, hızını, yoğunluğunu ve basıncını ifade ederken, $\theta_{\mathrm{f}}$ akışkan hacimsel oranını ve g yerçekimi ivmesini ifade etmektedir. F ise akışkan(baca gazı) ve partikül fazı arasında, birim hacimdeki momentum değișim oranını belirtmektedir. Liouville eşitliği kullanılarak zamana bağlı partikül dağılım fonksiyonu Denklem 4'te verilmiştir(Williams, 1985; Karimipour ve Pugsley, 2012).

$\frac{\partial \mathrm{f}}{\partial \mathrm{t}}+\nabla_{\mathrm{x}}\left(\mathrm{fu}_{\mathrm{p}}\right)+\nabla_{\mathrm{U}_{\mathrm{p}}}(\mathrm{fA})=0$

Denklem 4 ve 5 'te verilen parametrelerden $\mathrm{x}, \mathrm{u}_{\mathrm{p}}, \rho_{\mathrm{p}}, \mathrm{V}_{\mathrm{p}}$ sırasıyla, partikül pozisyonunu, hızını, yoğunluğunu ve, hacmini ifade etmektedir. Bu denklemde verilen $\mathrm{A}$, ortalama partikül ivmesi $\left(\mathrm{dU}_{\mathrm{p}} / \mathrm{d}_{\mathrm{t}}\right)$ olarak tanımlanmakta, Denklem 5'te verilen bağıntı ile hesaplanmaktır(Karimipour ve Pugsley, 2012).

$A=\frac{1}{\rho_{p}} D\left(u_{f}-u_{p}\right)-\frac{1}{\rho_{p}} \nabla_{x} P+g-\frac{1}{\theta_{p} \rho_{p}} \nabla_{x} \tau$
Denklem (5)'te verilen parametrelerden, $\theta_{\mathrm{p}}$, partikül hacimsel oranını, D sürüklenme katsayısını ve $\tau$ partiküller arasındaki kayma gerilmesini belirtmektedir. Tablo 5'te denklemleri verilen EMMSYang 2004 Sürüklenme Modeliyle kömür, yatak malzemesi ve kireç partikülleri üzerindeki akışkan sürüklenme kuvveti bulunmakta ve CFBB sistemi içerisindeki partikül ve gaz hidrodinamik akışın karakteristiğini belirleyen hız, sürüklenme kuvveti ve partikül hacimsel oranı değerleri belirlenmektedir. Tablo 5'te verilen $\mathrm{F}_{\mathrm{p}}$, partikül sürüklenme kuvvetini, $\mathrm{f}_{\mathrm{e}}$, Reynolds sayısı, akışın hacimsel oranı $\left(\theta_{\mathrm{f}}\right)$ ve $c_{\mathrm{o}}$ 'dan c14'e kadar, $\mathrm{n}_{\mathrm{o}}$ ve $\omega$ model sabitlerine bağlı bir fonksiyonu, $m_{p}$, partikül kütlesini, $\mu_{\mathrm{f}}$, akışkan viskozitesini, $r_{p}$, partikül çapını, $u_{p}$, partikül hızını, $u_{f}$, akışkan hızını, $\rho_{\mathrm{p}}$, partikül yoğunluğunu, $\rho_{\mathrm{f}}$, akışkan yoğunluğunu belirtmektedir.

Tablo 5. EMMS-Yang2004 sürüklenme modeli (Yang vd., 2004)

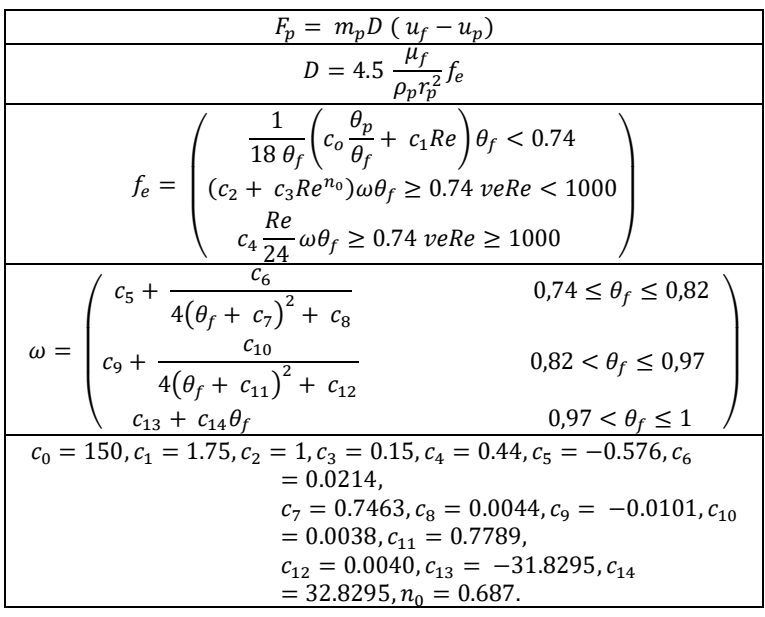

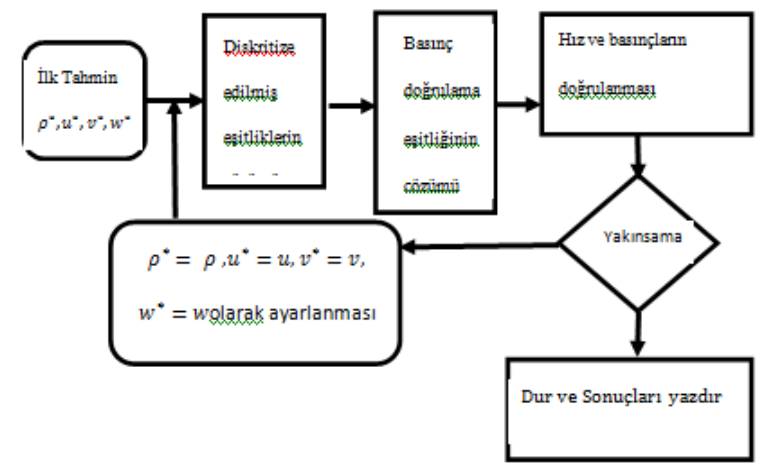

Şekil 5. Sayısal analizler için yapılan simulasyonlarda kullanılan SIMPLE Algoritması

Yanma sonucu oluşan gazların akışına yönelik sayısal analizler ve gerilme hesaplamaları için sırasıyla Denklem 6'da verilen Large Eddy Simulation(LES) türbülans metodu(Ku Shaari vd., 2015) ve Denklem 7 'te verilen gerilme tensörü denklemi ile tanımlanan Smagorinsky alt ağ yapısı kullanılmıştır(Smagorinsky, 1963). 
$\frac{\partial \rho \overline{\mathrm{u}}_{\mathrm{i}}}{\partial_{\mathrm{t}}} \operatorname{div}\left(\rho \overline{\mathrm{u}}_{\mathrm{i}} \rho \overline{\mathrm{u}}_{\mathrm{j}}\right)=-\frac{\partial\left(\overline{\mathrm{P}}_{\mathrm{i}}\right)}{\partial \mathrm{x}_{\mathrm{i}}}+\operatorname{div}\left(\Gamma \cdot \operatorname{grad} \overline{\mathrm{u}}_{\mathrm{i}}\right)-\frac{\partial \tau_{\mathrm{ij}}}{\partial \mathrm{x}_{\mathrm{j}}}$

$\tau_{i j}=\overline{\rho u_{t} u_{j}}+\rho \bar{u}_{i} \bar{u}_{j}$

Denklem 6 ve Denklem 7'teki $\overline{\mathrm{u}}_{\mathrm{i}}$ ve $\overline{\mathrm{P}}_{\mathrm{I}}$ sirasıyla hızı ve basıncl, $\tau_{i j}$ ise gerilme tensörünü ifade etmektedir. Denklem 8, Denklem 9 ve Denklem 10'da verilen parametreler, sonlu hacimler metodu kullanılarak hesaplanmaktadır.

$C_{i j}=\rho \bar{u}_{i} \rho u_{i}^{\prime} \bar{u}_{j}$

$L_{i j}=\left(\rho \bar{u}_{i} \rho \bar{u}_{j}-\rho \bar{u}_{i} \rho \bar{u}_{j}\right)$

$\mathrm{R}_{, \mathrm{ij}}=\rho \mathrm{u}_{\mathrm{i}}^{\prime} \mathrm{u}_{\mathrm{j}}^{\prime}$

\subsection{CFBB'de Isı Transfer Katsayılarının Hesaplanması}

Nümerik analizlerde, bölgesel olarak, hava-duvar arasındaki tașınımla ısı transfer katsayısı, Denklem 11 'de verilen bağıntıdan hesaplanmaktadır. Bu denklemde birinci terim, gaz fazının hacimsel oranının partikül fazına göre daha fazla olduğu seyrek gaz fazındaki taşınımla ısı transfer kat sayısını, ikinci terim ise yoğun partikül fazındaki tașınımla isı transfer kat sayısını ifade etmektedir.

$h=h_{f}+f_{d} h_{d}$

Burada, $\mathrm{f}_{\mathrm{d}}$,yoğun partikül fazındaki partiküllerin birbirine yaptığı temasların oranını belirtmektedir. Kazan içerisinde gaz fazındaki ısı transfer katsayısı, Douglas ve Churchill denklemi olarak adlandırılan Denklem 12 ve Denklem 13'te verilen bağıntılardan hesaplanmaktadır (Yang, 2003).

$\frac{h_{\mathrm{f}} \mathrm{L}}{\mathrm{k}_{\mathrm{f}}}=\mathrm{Nu}_{\mathrm{f}}=\mathrm{c}_{0} \mathrm{Re}_{\mathrm{L}}^{\mathrm{n}_{\mathrm{f}}}+\mathrm{c}_{1}$

$\operatorname{Re}_{\mathrm{L}}=\frac{\rho_{\mathrm{f}} \mathrm{u}_{\mathrm{f}} \mathrm{L}}{\mu_{\mathrm{f}}}$

Burada, $c_{0}=0,46, c_{1}=3,66$ ve $n_{f}=0,5$ olarak alınmıştır (Yang, 2003). Yoğun partikül fazları arasındaki ısı transfer katsayısı, Denklem 14 ve Denklem 15'te verilen bağıntılar kullanılarak hesaplanmaktır (Yang, 2003). Denklem 12,13 ve 14' te verilen, $d_{p}$, ortalama partikül çapını, $L$, akışkanın bir noktasının duvara uzaklığını ifade eden bölgesel karakteristik uzunluğu, $\mathrm{u}_{\mathrm{f}}$, akışkan hızını, $\mathrm{Nu}_{\mathrm{f}}, \mathrm{Nu}_{\mathrm{p}}, \rho_{\mathrm{f}}, \mu_{\mathrm{f}}$, parametreleri sirasiyla, zayıf gaz fazındaki Nusselt sayısını, yoğun partikül fazındaki Nusselt sayısını, akışkanın yoğunluğunu ve akışkanın dinamik viskozitesini ifade etmektedir.

$\frac{\mathrm{h}_{\mathrm{d}} \mathrm{d}_{\mathrm{p}}}{\mathrm{k}_{\mathrm{f}}}=\mathrm{Nu}_{\mathrm{p}}=\mathrm{c}_{0 \mathrm{p}} \operatorname{Re}_{\mathrm{p}}^{\mathrm{n}_{1 \mathrm{p}}}$
$\operatorname{Re}_{\mathrm{p}}=\frac{\rho_{\mathrm{f}} \mathrm{u}_{\mathrm{f}} \mathrm{d}_{\mathrm{p}}}{\mu_{\mathrm{f}}}$

Burada, $c_{0 p}=0,525$ ve $n_{1 p}=0,75$ olarak dikkate alınmıştır (Yang, 2003). Yoğun partikül fazındaki partiküllerin birbirine yaptığı temasların oranı Denklem 16'da verilen bağıntıdan hesaplanmaktadır.

$\mathrm{f}_{\mathrm{d}}=1-\mathrm{e}^{10\left(\theta_{\mathrm{p}} / \theta_{\mathrm{cp}}\right)}$

\section{4. ÇAN TS DAYK Sistemine Ait Sayısal Analizlerin Deneysel \\ Olarak Doğrulanması}

Sunulan bu çalışma kapsamında, 0,5 kW kapasiteli bir CFBB sistemi için yapılacak nümerik analizlerin doğrulanması amacıyla, öncelikle, ÇTS'ndeki CFBB sisteminin sayısal analizleri yapılmıştır. Sayısal analizlerle elde edilen sonuçlar, CTS'ne ait CFBB sistemine ait pratik sonuçlarla karşılaştırılmıştır. Bu karşılaștırmadan elde edilen sonuçlar Tablo 6'da verilmiştir. $\mathrm{Bu}$ tablodan da görüldüğü gibi, nümerik sonuçlarla, pratik sonuçların oldukça uyumlu olduğu görülmüștür.

Şekil 6'da, CTS CFBB sisteminin sayısal analizi sonucunda kazan tabanında, analiz bașlangıcından itibaren 200 s'lik zaman diliminde oluşan zamana bağlı sıcaklık dağılımı verilmiştir. Şekilden de görüleceği gibi, analizin ilk 160 s'si içerisinde, sıcaklık 1096 K'den 1091 K'e doğru kısmi bir düșüș gösterirken,160. s'den sonra yaklaşık 1091,33 K'de sabitlenmiștir.

Tablo 6. ÇTS CFBB sisteminde, yapılan analiz doğrulama çalışmalarına ait sonuçların karşılaştırılması

\begin{tabular}{|c|c|c|c|}
\hline $\begin{array}{c}\text { Karşılaştırılan } \\
\text { parametreler }\end{array}$ & $\begin{array}{l}\text { ÇAN TS } \\
\text { DAYK } \\
\text { sistemine } \\
\text { ait pratik } \\
\text { sonuçlar }\end{array}$ & $\begin{array}{c}\text { ÇAN TS } \\
\text { DAYK } \\
\text { sistemine ait } \\
\text { nümerik } \\
\text { analiz } \\
\text { sonuçları } \\
\end{array}$ & $\begin{array}{l}\text { Hata } \\
\text { yüzdesi } \\
(\%)\end{array}$ \\
\hline $\begin{array}{l}\text { Kazan tabanındaki } \\
\text { sicaklık (K) }\end{array}$ & 1100 & 1091,33 & 0,78 \\
\hline $\begin{array}{l}\text { Kazan çıkışındaki } \\
\mathrm{O}_{2} \text { mol oranı (\%) }\end{array}$ & 7,1 & 7,2 & 1,40 \\
\hline $\begin{array}{l}\text { Kazan çıkışındaki } \mathrm{NO}_{\mathrm{x}} \\
\text { emisyonu }\left(\mathrm{mg} / \mathrm{Nm}^{3}\right)\end{array}$ & 135 & 140,61 & 4,15 \\
\hline $\begin{array}{c}\text { Kazan çıkışındaki } \mathrm{SO}_{2} \\
\text { emisyonu }\left(\mathrm{mg} / \mathrm{Nm}^{3}\right)\end{array}$ & 765 & 731,5 & 4,3 \\
\hline $\begin{array}{l}\text { Kazan tabanındaki } \\
\text { basınç (kPa) }\end{array}$ & 107,885 & 108,401 & 0,47 \\
\hline $\begin{array}{l}\text { Kazan yanma odası } \\
\text { çıkışındaki basınç } \\
(\mathrm{kPa})\end{array}$ & 103415 & 103347 & 0,001 \\
\hline
\end{tabular}




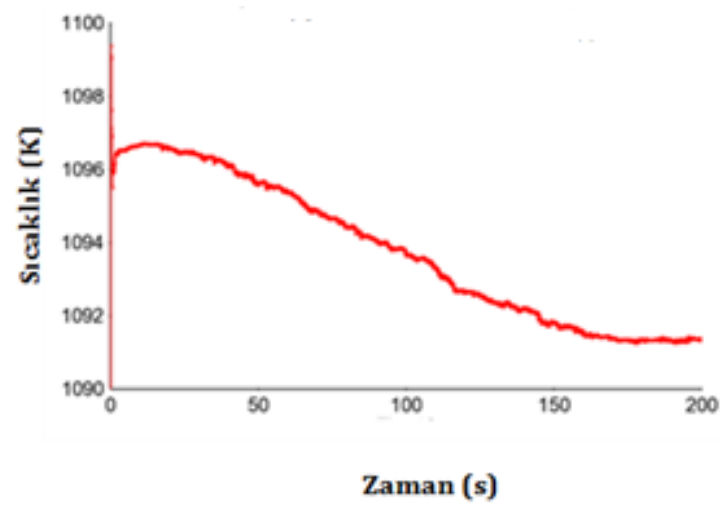

Şekil 6. CTTS CFBB sisteminde kazan tabanındaki zamana bağlı sıcaklık değişimi

\section{Araştırma Bulguları}

\subsection{Sayısal Analiz Sonuçları}

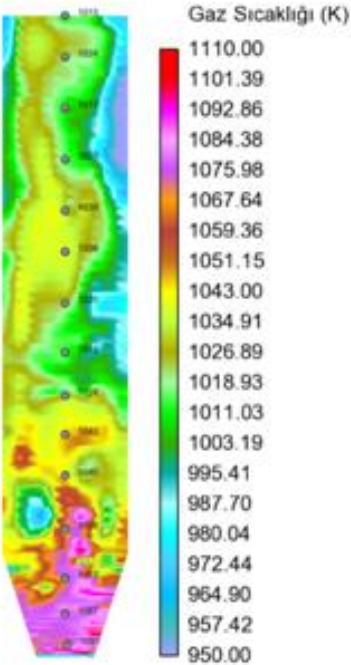

a)

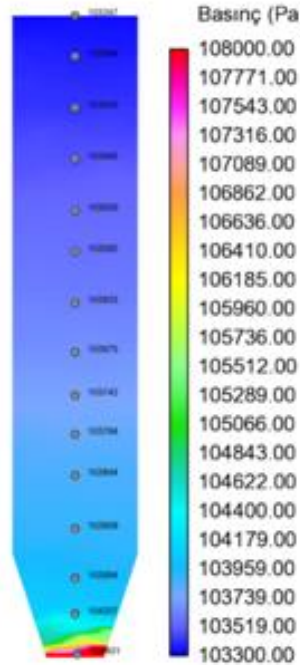

b)
Şekil 7. ÇTS kazanı (a) sıcaklık dağılımı, (b) basınç dağılımı

Şekil 7(a)'da görüldüğü gibi, sayısal analizler sonucunda, ÇTS kazan tabanındaki sıcaklık 1093 K, kazan çıkışında ise $1015 \mathrm{~K}$ olarak hesaplanmıştır. Bunun yan ısıra, Şekil 7 (b)'de verildiği gibi, ÇTS kazan tabanında basınç $108401 \mathrm{~Pa}$, kazan çıkışında ise 103347 Pa olarak hesaplanmıștır .

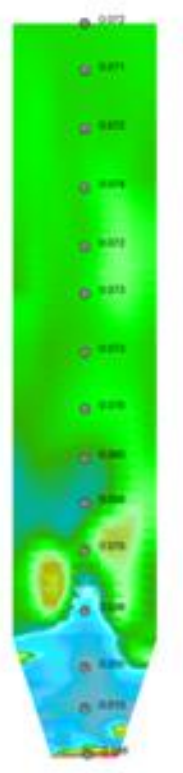

a)

\begin{tabular}{|l} 
O2 Mol Oran \\
0.19 \\
0.18 \\
0.17 \\
0.16 \\
0.15 \\
0.14 \\
0.13 \\
0.12 \\
0.11 \\
0.10 \\
0.09 \\
0.08 \\
0.07 \\
0.06 \\
0.05 \\
0.04 \\
0.03 \\
0.02 \\
0.01 \\
0.00
\end{tabular}

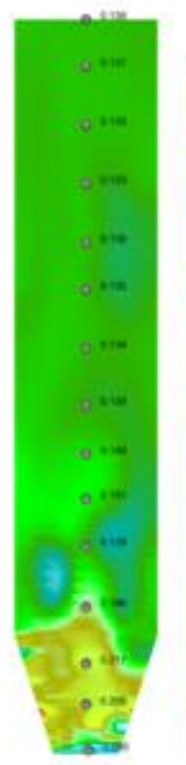

b)

Şekil 8. ÇTS kazanında yanma sonucu olușan gazların mol oranı dağılımı (a) $\mathrm{O}_{2}$ mol oranı dağılımı (b) $\mathrm{CO}_{2}$ mol oranı dağılımı

Şekil 8(a)'da görüldüğü gibi ÇTS kazan tabanında $\mathrm{O}_{2}$ mol oranı 0,01, kazan çıkışında ise 0,081 olarak hesaplanmıştır. Diğer yandan, Şekil 8 (b)'de görüldüğü gibi, ÇTS kazan tabanında $\mathrm{CO}_{2}$ mol oranı 0,04, kazan çıkışında ise 0,05 olarak hesaplanmıştır.

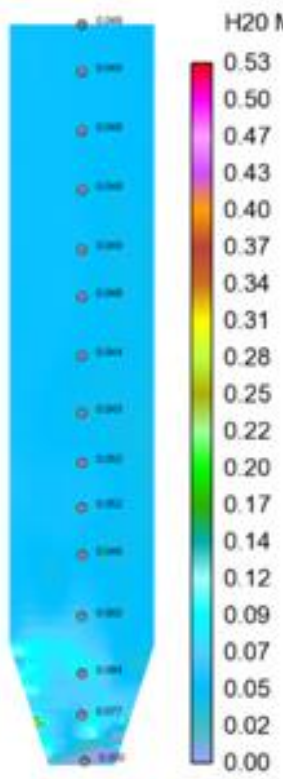

a)

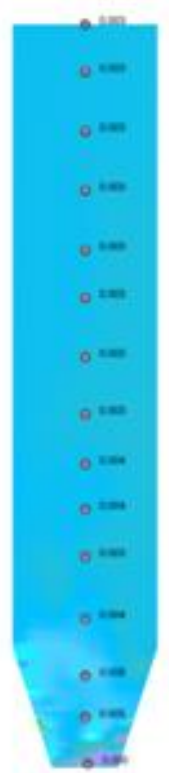

b)
SO2 Mol Oran
0.038
0.036
0.034
0.032
0.030
0.028
0.026
0.024
0.022
0.020
0.018
0.016
0.014
0.012
0.010
0.008
0.006
0.004
0.002
0.000

Sekil 9.CTS kazanında yanma sonucu olușan gazların mol oranı dağılımı (a) $\mathrm{H}_{2} \mathrm{O}$ mol oranı dağılımı (b) $\mathrm{SO}_{2}$ mol oranı dağılımı

Şekil 9(a)'da görüldüğü gibi, ÇTS kazan tabanında $\mathrm{H}_{2} \mathrm{O}$ mol oranı 0,077, kazan çıkışında 0,049 olarak hesaplanmıștır. Şekil 9 (b)'de kazan tabanında $\mathrm{SO}_{2}$ mol oranının0,005, kazan çıkışında ise 0,003 olarak hesaplandığı görülmektedir . 

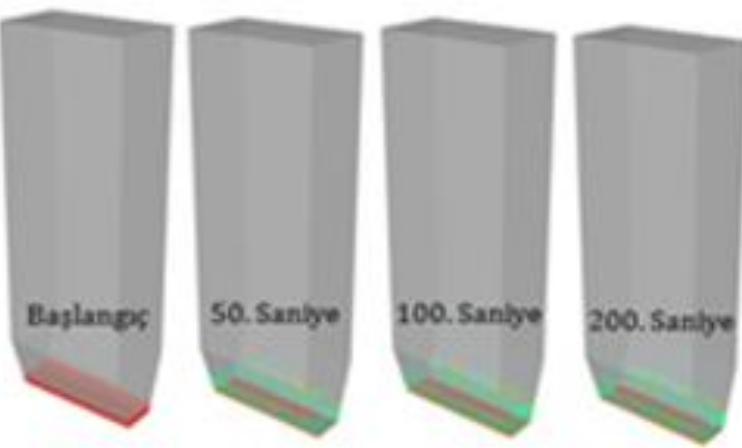

Şekil 10. ÇTS kazanı zamana bağlı yatak külü dağılımı

Şekil 10'da ÇTS kazanının yanma prosesi sürecinde zamana bağlı yatak külü dağılımı verilmiștir. Sayısal analiz sonuçlarına göre, kazanın ilk 200 s içerisinde istikrarlı çalışacağı görülmüştür. $\mathrm{Bu}$ nedenle yatak külünün zamana göre dağılımını gözlemlemek için 200 s'lik analiz zamanı seçilmiştir.

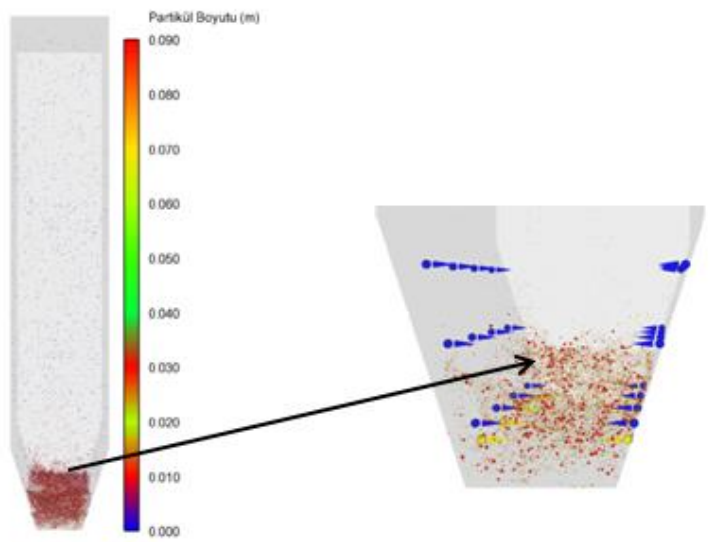

Şekil 11. ÇTS yatak külü partikül çapı dağılımı

Şekil 11'de ÇTS kazanı içerisindeki yatak külünün boyutsal dağılımı verilmiştir. Yanma odasının tabanından itibaren $1 \mathrm{~m}$ yükseklikten sonra yatak külü boyutu $60 \mu$ m'den, daha küçük boyutlara düşmektedir.

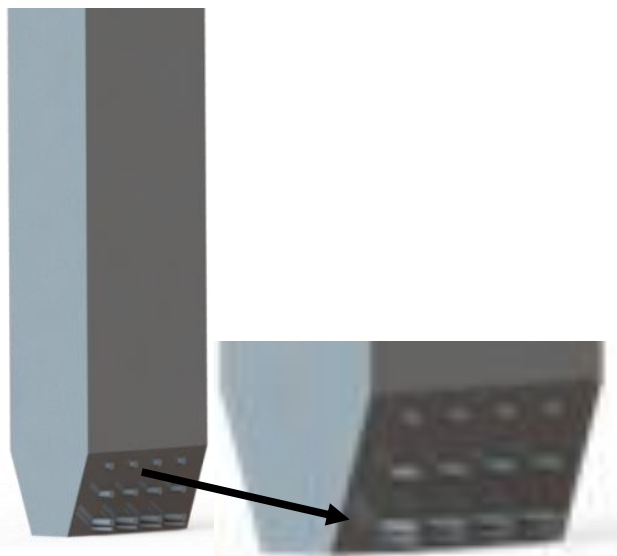

Şekil 12. ÇTS kazanı taban geometrisi
Şekil 12'de ÇTS kazanının 3D katı modeli görülmektedir. Yanma, kazan tabanından itibaren ilk 6 m yükseklikte gerçekleşmektedir. Kömür kazana, tabanından itibaren 0,5 m yukarıdaki bir noktadan gönderilmektedir. Bunun yanı sıra sekonder hava kazan tabanından itibaren 1., 3. ve 5.m'den kazana kademeli olarak beslenmektedir.

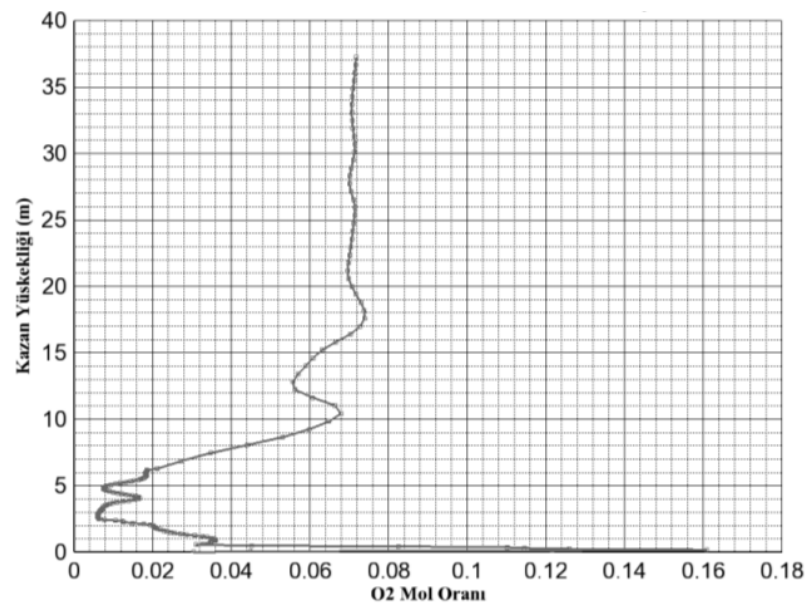

Şekil 13. ÇTS kazan yüksekliği- $\mathrm{O}_{2}$ mol oranı değișimi

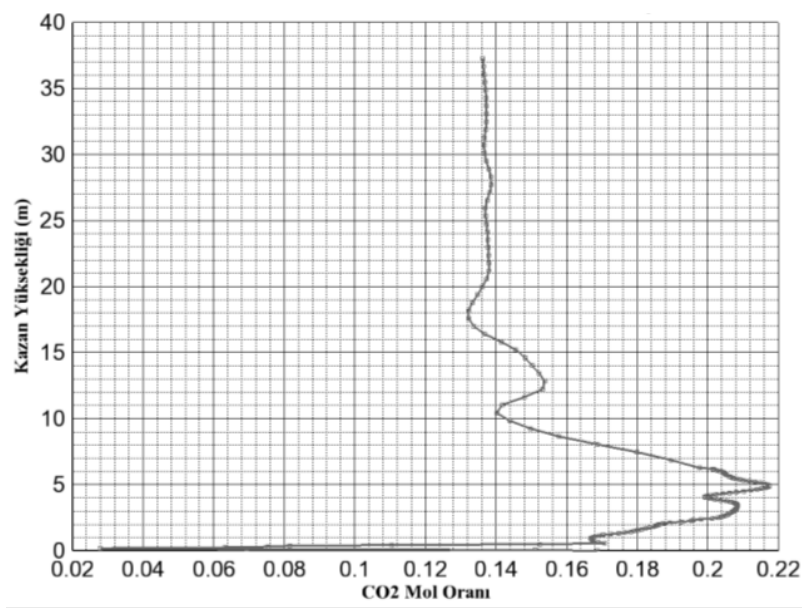

Şekil 14. ÇTS Kazanı yüksekliği- $\mathrm{CO}_{2}$ mol oranı değişimi

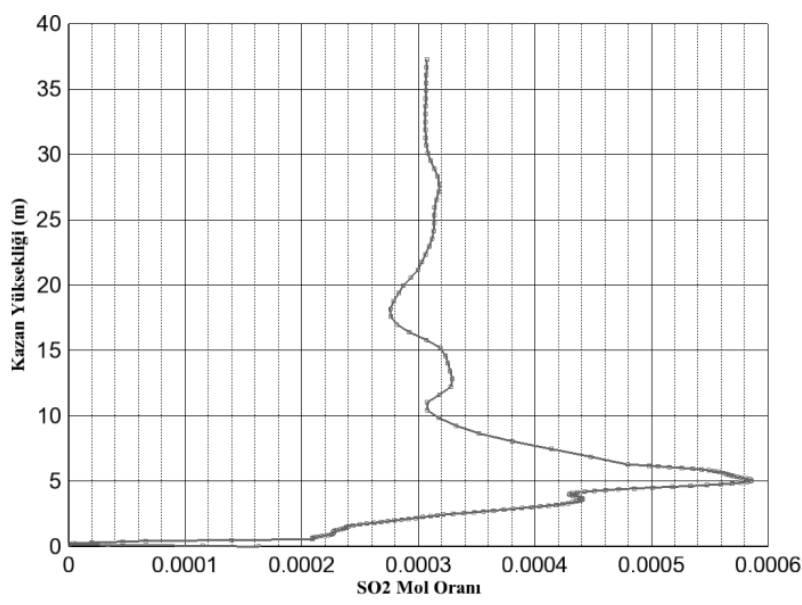

Şekil 15. ÇTS kazan yüksekliği- $\mathrm{SO}_{2}$ mol oranı değișimi 


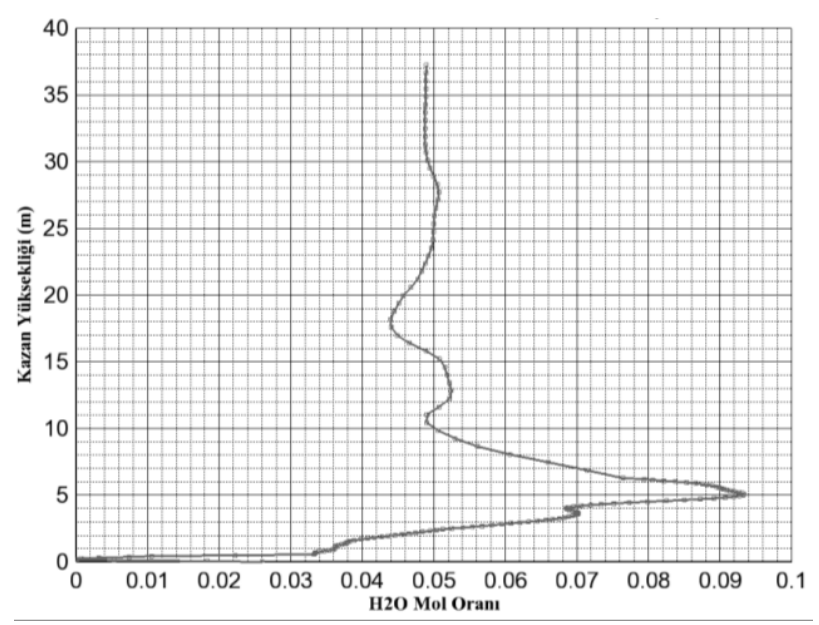

Şekil 16. Çan TS kazanı kazan yüksekliği- $\mathrm{H}_{2} \mathrm{O}$ mol oranı değișimi

Şekil 13 'te görüldüğü gibi, $8 \mathrm{~m}$ kazan yanma odası yüksekliğinde 0,09 değeriyle en yüksek $\mathrm{O}_{2}$ mol oranı oluşmaktadır. Daha sonra yanma odası çıkışında yanmanın tamamlanmasının ardından kazan yüksekliği boyunca $\mathrm{O}_{2}$ mol oranı $0,08-0,085$ aralığında sabit kalmaktadır.

Şekil 14, Şekil 15 ve Şekil 16'dan da görüldüğü gibi, benzer durum $\mathrm{CO}_{2}, \mathrm{SO}_{2}$ ve $\mathrm{H}_{2} \mathrm{O}$ mol oranları içinde ortaya çıkmaktadır. $8 \mathrm{~m}$ kazan yanma odası yüksekliğinde maksimum $\mathrm{CO}_{2} \mathrm{~mol}$ oranına $0,29, \mathrm{SO}_{2}$ mol oranina 0,0029 ve $\mathrm{H}_{2} \mathrm{O}$ mol oranina 0,38 değerlerinde ulaşılmaktadır. $\mathrm{Bu}$ noktadan itibaren yanma odası çıkışına kadar $\mathrm{CO}_{2}, \mathrm{SO}_{2}$ ve $\mathrm{H}_{2} \mathrm{O}$ mol oranları sirasiyla $0,05-0.06,0,003-0.004$ ve $0,05-0,055$ aralığında sabit kalmaktadır.

\section{Sonuç ve Tartışma}

Yapılan çalışmada, CPFD metodu ve ÇTS otomasyon odasından elde edilen sınır koşulları kullanılarak, 330 $M_{\text {th }}$ kapasitedeki CFBB'nin sayısal analizi gerçekleştirilmiştir. Sayısal analiz sonuçları ve ÇTS CFBB sisteminin pratik sonuçları karşılaştırılmıştır. Analiz doğrulama amacıyla yapılan bu analiz sonuçlarının sisteme ait pratik sonuçlarla uyumlu olduğu görülmüștür. CPFD metodu kullanılarak farklı kapasitelerde CFBB sistemlerinin tasarımlarının yapılabileceği gözlemlenmiştir. Analizlerde, yanma odasındaki basınç ve sıcaklık dağılımlarının yanı sıra, $\mathrm{O}_{2}, \mathrm{CO}_{2}, \mathrm{H}_{2} \mathrm{O}$ ve $\mathrm{SO}_{2}$ mol oranlarındaki değişimler araştırılmıştır.

Araştırma sonuçlarına göre, kazan tabanımdaki basıncın kazan çıkışına kadar 50,54 kPa azalmıștır. Aynı şekilde sıcaklık kazan tabanından çıkışına kadar $78^{\circ} \mathrm{C}$ düşmektedir. $\mathrm{H}_{2} \mathrm{O}$ ve $\mathrm{SO}_{2}$ mol oranları sirasıyla 0,028 ve 0,002 düşmüştür. $\mathrm{O}_{2}$ ve $\mathrm{CO}_{2}$ mol oranları ise sırasıyla 0,071 ve 0,01 artmıștır.

Çalışma sonucunda CPFD metodunun faal durumda ve gerçek kapasitelerdeki yakma sistemlerinin modellenmesinde oldukça başarılı olduğu görülmüştür. Çalışma kapsamında gerçekleştirilen matematiksel modellemede yanma karakteristikleri ve basınç dağılımı yanı sıra, emisyonlar ve partiküllerin hidrodinamik akışı da modellenebilmektedir.

Gelecekte yapılacak çalışmalarda doğrulanan sayısal model kullanılarak, $\quad 0,5-100 \quad \mathrm{MW}_{\text {th }}$ kapasite aralığındaki CFBB sistemlerinin tasarımları ve optimize yapılabilecektir. Bu durum ülkemiz gibi yüksek miktarda düşük kaliteli linyit yakıtlarasahip olan bir ülkelerin bu yakıtların değerlendirilebilmesi amaciyla yeni CFBB sistemlerinin tasarlanmasinda önemli bir avantaj sağlayacaktır.

\section{Çıkar Çatış̧ması}

Yazarlar tarafından herhangi bir çıkar çatışması beyan edilmemiştir.

No conflict of interest was declared by the authors.

\section{Kaynaklar}

AB LCP Direktifi, 2001. The Large Combustion Plant Directive LCPD, 2001/80/EC, Erişim Tarihi: 28.07.2015. http://eur-lex.europa.eu/legalcontent/EN/TXT/?uri=CELEX:32001L0080.

Batchelor, G.K., 1988. A New Theory of the Instability of a Uniform Fluidized Bed. Journal of Fluid Mechanics, 193, 75-110.

Borgwardt, R.H., Bruce, K.R., Blake, J., 1987. An Investigation of Product-Layer Diffusivity for $\mathrm{CaO}$ Sulfation. Industrial and Engineering Chemistry Research, 26(10), 1993-1998.

Chen, J.,Yao, H., Zhang, L., 2012, A Study on the Calcination and Sulphation Behaviour of Limestone During Oxy-fuel Combustion. Fuel, 102, 386-395.

CPFD Barracuda User Guide, 2015.

Dennis, J.S.,Hayhurst, A.H., 1990. Mechanism of the Sulphation of Calcined Limestone Particles in Combustion Gases. ChemEngSci, 45, 1175-1187.

Ducarne, E.D., Dolignier, J.C., Marthy, E., Martin, G., Delfosse, L., 1998. Modelling of Gaseous Pollutants Emissions in Circulating Fluidized Bed Combustion of Municipal Refuse. Fuel 77, 1399-1410.

Duo, W., Dam-Johansen, K.,Ostergaard, K.,1992. Kinetics of the Gas Phase Reaction Between NitricOxide, Ammonia and Oxygen. Canadian Journal of Chemical Engineering, 70(5), 1014-1020.

Farid, M.M., Jeong, H.J., Kim, K.H., Lee, J., Kim, D., Hwang, J., 2017. Towards a Hybrid EulerianLagrangian CFD Modeling of Coal Gasification in a 
Circulating Fluidized Bed Reactor, Fuel, 152, 131137.

Feng, Y.,Swenser-Smith, T., Witt, P.J., Doblin, C., Lim, S., Schwarz M.P., 2012. CFD Modeling of Gas-Solid Flow in an Internally Circulating Fluidized Bed. PowderTechnology, 219, 78-85.

Gan, J., Zhou, Z., Yu, A., 2016. Particle Scale Study of Heat Transfer in Packed and Fluidized Beds of Ellipsoidal Particles. Chemical Engineering Science, 144, 201-215.

Gasparini, F., Papa, I., Criner, K., Mary, S., Coal OxyCombustion in a CHP Plant Using the Circulating Fluidized Bed (CFB) BoilerTechnology, PowerGen Europe, 12-14 June 2012, Colon, Germany. http://www.fwc.com/getmedia/e3c64ca2-e5584b77-ba3d

e77306bbcea7/TP_CFB_12_09.pdf.aspx?ext=.pdf.

Gidaspow, D., 1994. Multiphase Flow and Fludization Continuum and Kinetic Theory Description. Academic Press, Boston.

Gungor, A., \& Eskin, N. 2008. Two-dimensional Coal Combustion Modeling of CFB. International Journal of Thermal Sciences, 47(2), 157-174.

Gül, S., Özdoğan, Z.S., 2016. Ejector Type Solid Circulation System Analysis for Circulating Fluidized Beds. International Journal of Multiphase Flow, 84, 116-128.

Jiang Y.,Qiu G., Wang H., 2014. Modelling and Experimental Investigation of the Full-Loop GasSolid Flow in Circulating Fluidized Bed with Six Cyclone Separators. Chemical Engineering Science, 109, 85-97.

Johnsson, J.E., Dam-Johansen, K.,1991. Formation and Reduction of in a Fluidized Bed Combustor. 11th International Conference on Fluidized Bed Combustion, ASME, 1389-1396.

Karimipour, S., Pugsley, T., 2012. Application of the Particle in Cell Approach for the Simulation of Bubbling Fluidized Beds of Geldart a Particles. Powder Technology, 220, 63-69.

Kilpinen, P.,Kallio, S., Konttinen, J., \&Barišić, V. 2002. Char-nitrogen Oxidation Under Fluidised Bed Combustion Conditions: Single Particle Studies. Fuel, 81(18), 2349-2362.

Kraft, S., Kimbauer, F., Hofbauer, H., 2017. CPFD Simulations of an Industrial-sized Dual Fluidized Bed Steam Gasification System of Biomass with 8 MW Fuel Input. Applied Energy, 190, 408.

Ku Shaari, Ku.Z., Awang, M., 2015. Engineering Applications of Computational Fluid Dynamics.
VIII, 167, 108, Hardcover, ISBN: 978-3-319-028354.

Liu, H., Feng, B., Lu, J.D., 2005. Coal Property Effects on N2O and NOX Formation from Circulating Fluidized Bed Combustion of Coal, Chemical Engineering Communications, 192, (10-12), 14821489

Özkan, M., 2010. Simulation of Circulating Fluidized Bed Combustors Firing Indigenous Lignite. Master Thesis, Orta Doğu Teknik Üniversitesi Fen Bilimleri Enstitüsü, 134s, Ankara.

Pandey, K.M., Kumar, R., 2011. Numerical Analysis of Coal Combustion in Circulating Fluidized Bed. International Journal of Chemical Engineering and Applications, 2(6), 390-394.

Smagorinsky, J., 1963. General Circulation Experiments with the Primitive Equations, part I: the Basic Experiment, Monthly Weather Review, 91, 99-164.

Weng, M.,Plackmeyer, J., 2011. Comparison Between Measurements and Numerical Simulation of Particle Flow and Combustion a the CFBC Plant. 10th International Conference on Circulating Fluidized Beds And Fluidization Technology (CFB10), 3-5 Spring 2011, Duisburg. http://dc.engconfintl.org/cfb10/61/

Williams, F.A., 1985. Combustion Theory, Benjamin/Cummings, Menlo Park, California, 2nd Edition.

Yang, N.,Wang, W., Ge, W., Wang, L., \&Li, J. 2004 Simulation of Heterogeneous Structure in a Circulating Fluidized-Bed Riser by Combining the Two-Fluid Model with the EMMS Approach. Industrial \& Engineering Chemistry Research, 43(18), 5548-5561.

Yang, Wen-Cin, 2003. Handbook of Fluidization and Fluid-ParticleSystem. Marcel Dekker, The NewYork, (a) p267 and (b) p2 62. 